\title{
Comparison of Innervation and Agrin-induced Tyrosine Phosphorylation of the Nicotinic Acetylcholine Receptor
}

\author{
Zhican Qu and Richard L. Huganir \\ Department of Neuroscience, Howard Hughes Medical Institute, The Johns Hopkins University School of Medicine, \\ Baltimore, Maryland 21205
}

\begin{abstract}
Studies of the regulation of tyrosine phosphorylation at the neuromuscular junction during development and following denervation suggest that tyrosine phosphorylation of the nicotinic acetylcholine receptor is regulated by neuronal innervation of muscle. The finding that agrin, a neuronally derived extracellular matrix protein also induces tyrosine phosphorylation of the nicotinic receptor, suggests that nerveinduced tyrosine phosphorylation may be mediated by agrin. To study this further, we have examined the regulation of tyrosine phosphorylation of the nicotinic receptor by innervation in vitro using muscle-neuron cocultures. Innervation of chick myotubes by chick ciliary ganglia neurons induced tyrosine phosphorylation of the nicotinic receptor with the same subunit specificity seen with bath applied purified agrin. Both innervation and agrin-induced phosphorylation of the nicotinic receptor resulted in an increase in tyrosine and serine phosphorylation. In addition, thermolysin phosphopeptide maps of the subunits after innervation or agrin-treatment were identical. The similarity in the agrin- and nerve-induced phosphorylation of the acetylcholine receptor suggests that agrin mediates the nerve-induced phosphorylation during development in vivo and that phosphorylation of the acetylcholine receptor may play an important role in the development of the neuromuscular junction.
\end{abstract}

[Key words: phosphotyrosine, tyrosine kinases, neuromuscular junction, synapses, synaptogenesis]

Protein phosphorylation is widely recognized as one of the primary mechanisms for the regulation of cellular function (Edelman et al., 1987). Recent studies have shown that phosphorylation of neurotransmitter receptors plays an important role in the modulation of synaptic transmission (Swope et al., 1992; Raymond et al., 1993). The nicotinic acetylcholine receptor (AChR) mediates signal transduction at the neuromuscular junction and has served as an excellent model for the structure, function, and regulation of neurotransmitter-gated ion channels (Galzi et al., 1991). The AChR from the electric organ of Torpedo and skeletal muscle is a pentameric complex of four different subunits in a stoichiometry of $\alpha_{2} \beta \gamma \delta$ (Galzi et al., 1991)

\footnotetext{
Received Jan. 6, 1994; revised Apr. 20, 1994; accepted May 11, 1994.

We thank Dr. Jon Lindstrom and Dr. Stanley Froehner for generously providing monoclonal antibodies, Cindy Finch for excellent secretarial support, and Drs. Richard O'Brien, Sheridan Swope, and Lin Mei for helpful comments on the manuscript.

Correspondence should be addressed to Richard L. Huganir, Ph.D., Department of Neuroscience, Howard Hughes Medical Institute, The Johns Hopkins University School of Medicine, 725 North Wolfe Street, 900 Preclinical Teaching Building. Baltimore, MD 21205-2185.

Copyright (c) 1994 Society for Neuroscience $0270-6474 / 94 / 146834-08 \$ 05.00 / 0$
}

that has been shown to be phosphorylated in vivo and in vitro by at least three different protein kinases (Swope et al., 1992). cAMP-dependent protein kinase (PKA) phosphorylates the $\gamma$ and $\delta$ subunits (Huganir and Greengard, 1983; Zavoico et al., 1984), protein kinase C (PKC) phosphorylates the $\delta$ subunit (Huganir, 1987; Safran et al., 1987), and a protein tyrosine kinase phosphorylates the $\beta, \gamma$, and $\delta$ subunits (Huganir et al., 1984; Hopfield et al., 1988).

The extracellular signals that regulate phosphorylation of the AChR in muscle have been investigated (Ross et al., 1988; Miles et al., 1989; Qu et al., 1990). Phosphorylation of the receptor by PKA is regulated by the neuropeptide calcitonin gene-related peptide (CGRP) (Miles et al., 1989), which is a cotransmitter with acetylcholine at the neuromuscular junction. Treatment of cultured rat myotubes with CGRP induces cAMP accumulation and phosphorylation of the AChR on the $\alpha$ and $\delta$ subunit. Acetylcholine itself regulates phosphorylation of the $\delta$ subunit of the $\mathrm{AChR}$ in cultured chick and rat myotubes through a process that is dependent on extracellular calcium and is abolished by AChR channel blockers (Ross et al., 1988; Miles et al., 1993). In addition, recent studies have suggested that tyrosine phosphorylation of the $\mathrm{AChR}$ at the neuromuscular junction is regulated by innervation in vivo, apparently through the release of a nerve-derived factor (Qu et al., 1990). Moreover, studies have shown that treatment of cultured myotubes with the neuronal extracellular matrix protein agrin, caused an increase in tyrosine phosphorylation of the AChR (Wallace et al., 1991).

Agrin is an extracellular matrix protein that was originally purified from Torpedo electric organ based on its ability to induce clustering of acetylcholine receptors in cultured chick myotubes (Nitkin et al., 1987; McMahon, 1990). Several cDNA clones for agrin have been isolated (Rupp et al., 1991; Tsim et al., 1992), and recent studies have shown that agrin exists in alternatively spliced forms that differ in their ability to induce AChR clusters (Ferns et al., 1992, 1993; Tsim et al., 1992). The most active splice varients of agrin appear to be synthesized by the motoneuron, transported to nerve terminals, and inserted into the synaptic basal lamina of the neuromuscular junction (Magill-Solc and McMahan, 1990; Cohen and Godfrey, 1992; Reist et al., 1992; Hoch et al., 1993). A variety of studies have suggested that agrin mediates the nerve-induced aggregation of the AChRs beneath the nerve terminal (McMahon, 1990). Treatment of cultured chick myotubes with purified or recombinant agrin induces clustering of many components of the postsynaptic apparatus including AChRs, acetylcholinesterase, a heparan sulfate proteoglycan, and the $43 \mathrm{kDa} A C h R$-associated protein (Wallace, 1986, 1989; Nitkin et al., 1987; Campanelli et al., 1991; Tsim et al., 1992). In addition, treatment of chick 

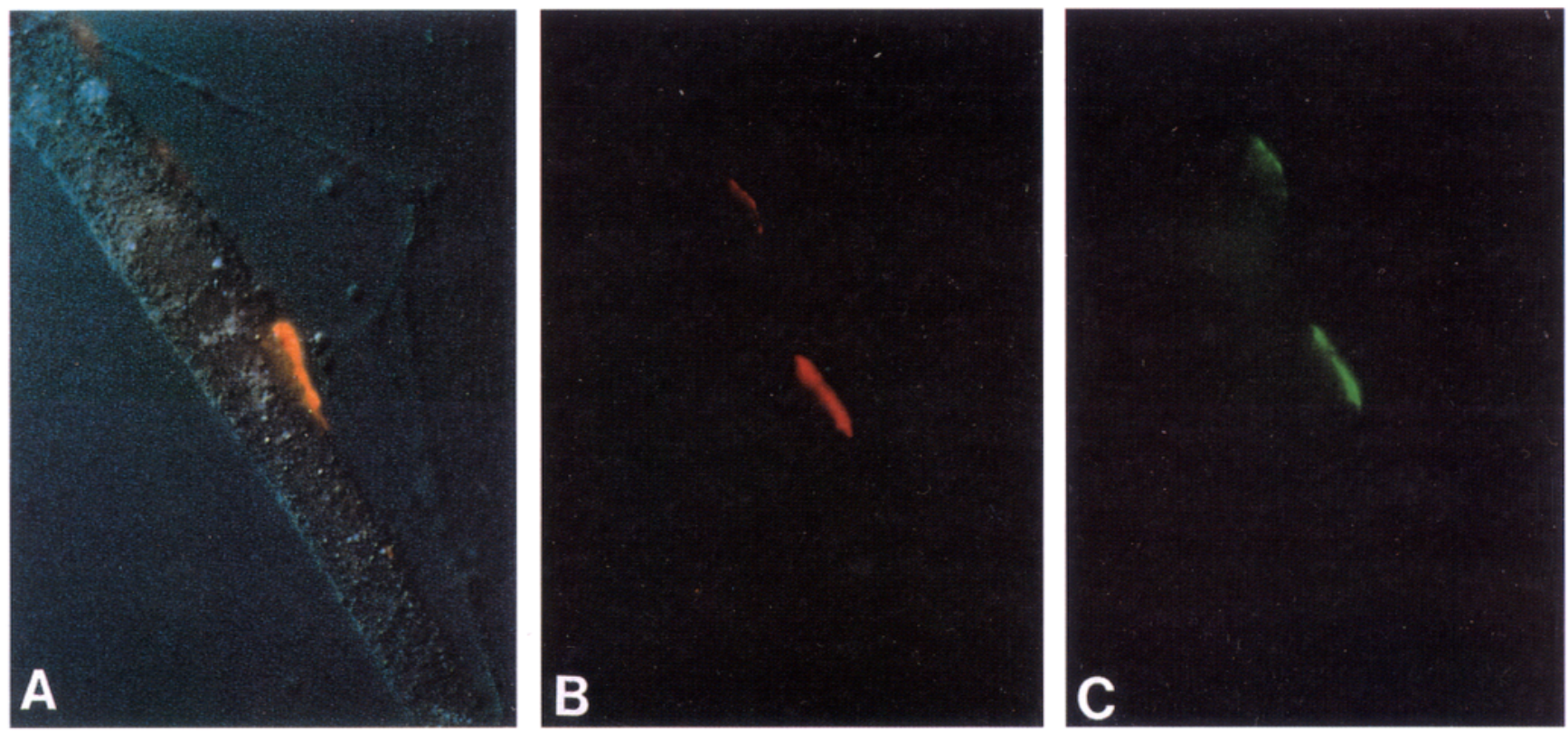

Figure 1. Regulation of tyrosine phosphorylation of the AChR by innervation in chick neuron-muscle cell coculture. Chick ciliary ganglion neuron and muscle cell cocultures were fixed, permeabilized, and double labeled with rhodamine-conjugated $\alpha$-bungarotoxin and monoclonal anti-phosphotyrosine antibodies and fluorescent-conjugated secondary antibodies. Rhodamine-conjugated $\alpha$-bungarotoxin staining of AChR clustering occurred at synapses of neurons with muscle cells $(A$ and $B)$, and colocalized with high levels of phosphotyrosine $(C)$.

motor neuron-chick muscle cocultures with antibodies to agrin inhibited formation of nerve-induced AChR clusters (Reist et al., 1992). The mechanism of agrin-induced clustering of the $\mathrm{AChR}$, however, remains unclear. In this study we investigated whether agrin may be the nerve-derived factor that regulates tyrosine phosphorylation of the AChR at the neuromuscular junction by examining the effect of innervation on the tyrosine phosphorylation of the AChR on cultured myotubes, and comparing it with agrin-induced tyrosine phosphorylation. Our results suggest that nerve-induced tyrosine phosphorylation of the $\mathrm{AChR}$ at the neuromuscular junction is mediated by agrin, and that tyrosine phosphorylation may play an important role in the developmental regulation of the AChR and the neuromuscular junction.

\section{Materials and Methods}

Immunocytochemical localization of AChRs and phosphotyrosine. Neuron/muscle cocultures were fixed with $3 \%$ paraformaldehyde in $0.1 \mathrm{M}$ sodium phosphate $(\mathrm{pH} \mathrm{7.3)}$ for $30 \mathrm{~min}$ at room temperature and then permeabilized and blocked with $6 \%$ BSA and $0.2 \%$ Triton X-100 in PBS for $10 \mathrm{~min}$. The permeabilized cocultures were incubated with rhodamine-conjugated $\alpha$ - bungarotoxin and a monoclonal antibody against phosphotyrosine (PY20; ICN ImmunoBiologicals, Costa Mesa, $\mathrm{CA}$ ), incubated with fluorescein-conjugated secondary antibody (Jackson Laboratories, West Grove, PA), and examined and photographed with a Zeiss Axiophot fluorescence microscope equipped with rhodamine and fluorescein optics.

Immunofluorescent staining of chick skeletal muscles. Prenatal and postnatal chick leg muscles were dissected, frozen as rapidly as possible, and then sectioned and rapidly fixed in $3.0 \%$ paraformaldehyde for 30 $\mathrm{min}$ at room temperature. Sections $(6 \mu \mathrm{m})$ were incubated for $30 \mathrm{~min}$ at room temperature in PBS with rhodamine-conjugated $\alpha$-bungarotoxin to visualize the $\mathrm{AChR}$ and a monoclonal antibody specific against phosphotyrosine (PY20), and subsequently incubated with fluoresceinconjugated secondary anti-mouse antibody (Jackson Laboratories, West Frove, PA) to visualize phosphotyrosine.

Antibodies. Anti-phosphotyrosine antibodies were prepared by immunizing rabbits with phosphotyrosine conjugated to BSA or $\mathrm{KLH}$ (Hirano et al., 1988). The resulting serum was affinity purified on a phosphotyrosine affinity column prior to use. The monoclonal antibody against phosphotyrosine (PY20) was originally isolated in Dr. John Glenney's laboratory (Salk Institute, La Jolla, CA) and was obtained from ICN. Subunit-specific monoclonal antibodies raised against Torpedo californica and eel AChRs were provided by Dr. Jon Lindstrom (University of Pennsylvania, Philadelphia, PA), who furnished \#61 (anti$\alpha$ subunit) and \#124 (anti- $\beta$ subunit), and by Dr. Stanley C. Froehner (University of North Carolina, Chapel Hill, NC), who furnished \#88b (anti- $\delta / \gamma$ subunit). These monoclonal antibodies specifically cross-reacted with $\mathrm{AChR}$ subunits isolated from chick myotubes.

Chick myotube cultures and neuron/muscle cell cocultures. Myotube cultures were prepared from hindlimb muscles of 11-12-d-old White Leghorn chick embryos by the method of Fischbach (1972). Experiments were routinely done on 5-d-old cultures. Ciliary ganglia were dissected from 8- or 9-d-old chick embryos and dissociated in $0.05 \%$ trypsin 20 $\mathrm{min}$ at $37^{\circ} \mathrm{C}$. Ciliary ganglion cells $(10-15$ ganglia per $10 \mathrm{~cm}$ plate) were added to chick myotubes that had been cultured for $3 \mathrm{~d}$ (Fischbach, 1972). For metabolic labeling with radioactive phosphate, myotubes were prelabeled with ${ }^{32} \mathrm{P}$-orthophosphate for $12 \mathrm{hr}$ in phosphate-free media prior to cell harvesting. To examine the effect of agrin and neurons on phosphorylation, agrin and neurons were added 12 and $48 \mathrm{hr}$, respectively, prior to harvesting the myotubes.

Purification of agrin. Agrin was partially purified from the electric organ of Torpedo californica as previously described (Godfrey et al., 1984; Nitkin et al., 1987). The electric organs were quickly removed and homogenized in buffered saline at $4^{\circ} \mathrm{C}$ and then centrifuged. The supernatant was discarded and the pellet was homogenized and centrifuged twice. The pellet was resuspended in $3 \%$ Triton, $10 \mathrm{~mm}$ Tris- $\mathrm{HCl}$ (pH 7.5), $150 \mathrm{~mm} \mathrm{NaCl}, 1 \mathrm{~mm}$ EGTA, and $1 \mathrm{~mm}$ EDTA with Teflonglass homogenizer, and then stirred $30 \mathrm{~min}$ at $4^{\circ} \mathrm{C}$. The suspension was centrifuged, and the pellet was reextracted with buffered Triton solution and then centrifuged. The pellet was resuspended and homogenized in $0.2 \mathrm{~m}$ sodium bicarbonate, $5 \%$ glycerol, $0.02 \%$ sodium azide ( $\mathrm{pH} 9.0$ ), stirred overnight at $4^{\circ} \mathrm{C}$, rehomogenized, and centrifuged. The supernatant was applied to a $15 \mathrm{ml}$ column of Cibacron Blue 3GA-Agarose (Affi-gel Blue Gel, 100-200 mesh; Bio-Rad Laboratories, Richmond, CA) equilibrated in bicarbonate buffer. The column was washed with 10 column volumes of bicarbonate buffer and eluted with $1.5 \mathrm{M} \mathrm{NaCl}$ in bicarbonate buffer. Fractions with the highest specific activity, as measured by induction of AChR clustering in cultured chick myotubes, were pooled.

SDS polyacrylamide gel electrophoresis and immunoblot analysis. Samples were electrophoresed on $8 \%$ SDS polyacrylamide gels (Laemm- 


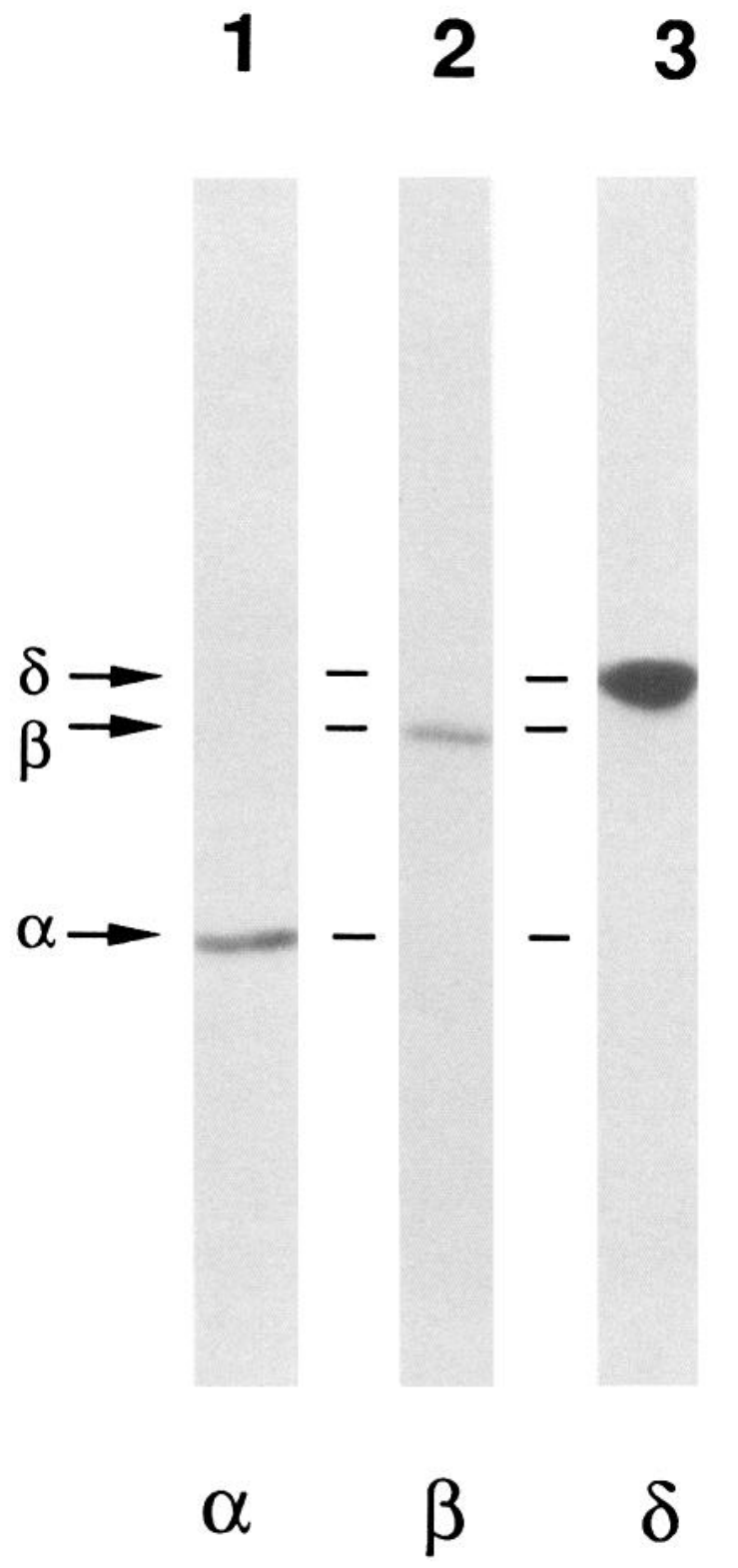

Figure 2. Immunoblot of the AChR from cultured chick myotubes with AChR subunit-specific antibodies. Purified preparations of the $\mathrm{AChR}$ from chick muscle cultures were isolated by acetylcholine affinity chromatography and analyzed by immunoblot techniques using specific monoclonal antibodies against the AChR subunits. The $40 \mathrm{kDa}$ and 52 $\mathrm{kDa}$ polypeptides were identified as the $\alpha$ subunit and the $\beta$ subunit, respectively. A polypeptide with an apparent molecular weight of 56 $\mathrm{kDa}$ was identified as the $\delta$ subunit.

li, 1970) and then transferred to nitrocellulose (Towbin, 1979). The blots were probed with 100-1000-fold dilutions of affinity purified antiphosphotyrosine antibodies (Hirano et al., 1988) and with monoclonal antibodies against the AChR. The primary antibody was labeled with horseradish peroxidase-linked secondary antibody (from Amersham) and visualized by the enhanced chemiluminescence (ECL; Amersham) technique. The ECL autoradiograph was quantitated with an LKB laser densitometer.

Two-dimensional phosphopeptide maps. Gels were dried and the gel pieces containing the proteins of interest were cut out. Because the $\beta$ and $\delta$ subunits were poorly resolved, we combined these two subunits for phosphopeptide map analysis. The phosphorylated proteins were digested with $0.15 \mathrm{mg} / \mathrm{ml}$ thermolysin as described (Huganir et al., 1984) and spotted on cellulose thin-layer plates. The cellulose plates were subjected to electrophoresis in first dimension followed ascending chro- matography in second dimension. The plates were then dried and autoradiographed (Huganir et al., 1984).

Phosphoamino acid analysis. Gels were dried and the gel pieces containing the proteins of interest were cut out. Because the $\beta$ and $\delta$ subunits were poorly resolved, we combined these two subunits for phosphoamino acid analysis. The phosphorylated proteins were digested with $0.15 \mathrm{mg} / \mathrm{ml}$ thermolysin and then hydrolyzed with $6 \mathrm{M} \mathrm{HCl}$ at $105^{\circ} \mathrm{C}$ for $1.5 \mathrm{hr}$ as described previously (Miles et al., 1989). The acid-hydrolyzed amino acids were then applied on cellulose thin-layer plate and subjected to one-dimensional thin layer electrophoresis. The cellulose plate was dried and subjected to autoradiography to identify the ${ }^{32} \mathrm{P}$ labeled phosphoamino acids (Hirano et al., 1988) or examined by PhosphoImager 4000E system (Molecular Dynamics) for quantitative analysis.

Purification of the AChR from myotube cultures by acetylcholine affinity chromatography and immunoprecipitation. Cultured myotubes were rinsed with warm PBS, and AChRs were solubilized from each culture dish by using an ice-cold lysis solution containing $2 \%$ Triton, $20 \mathrm{~mm}$ $\mathrm{KPO}_{4}$ buffer (pH 7.4), $150 \mathrm{~mm} \mathrm{NaCl}, 10$ mм EDTA, 10 mм EGTA, $10 \mathrm{~mm}$ sodium pyrophosphate, $50 \mathrm{~mm} \mathrm{NaF}, 1 \mathrm{~mm} \mathrm{Na}_{3} \mathrm{VO}_{4}$ (ortho), 10 mM iodoacetamide, $0.1 \mathrm{mM}$ phenylmethylsulfonyl fluoride, $10 \mu \mathrm{g} / \mathrm{ml}$ leupetin, $10 \mu \mathrm{g} / \mathrm{ml}$ pepstatin, $10 \mu \mathrm{g} / \mathrm{ml}$ chymostatin, $10 \mu \mathrm{g} / \mathrm{ml}$ antipain, $10 \mathrm{U} / \mathrm{ml}$ Trasylol, and $20 \mathrm{~mm}$ benzamide. Insoluble material from each culture extract was removed by centrifugation for $10 \mathrm{~min}$ at $10,000 \times$ $g$ and the supernatant containing AChRs were passed through individual acetylcholine affinity columns (Reynolds and Karlin, 1978), which were then washed with lysis solution. For Western blot analysis, the AChR subunits were eluted from the affinity resin with SDS sample buffer containing $125 \mathrm{~mm}$ Tris $\cdot \mathrm{HCl}(\mathrm{pH} 6.8), 2 \%$ (w/v) SDS, $10 \%$ (v/v) glycerol, and $5 \%(\mathrm{v} / \mathrm{v}) \beta$-mercaptoethanol and subjected to electrophoresis. For the ${ }^{32} \mathrm{P}$-phosphate prelabeling experiments, the AChR complexes were eluted from the affinity resin with lysis solution containing $25 \mathrm{~mm}$ carbamylcholine. The eluate from each acetylcholine affinity column were then subjected to immunoaffinity chromatography. The eluate were passed through individual immunoaffinity columns consisting of monoclonal antibody $88 \mathrm{~b}$ linked to protein A-Sepharose (Pharmacia, Piscataway, NJ) by a rabbit anti-mouse IgG (DAKO, Santa Barbara, CA). The columns were washed with lysis solution, and the AChR subunits were eluted from the immunoaffinity columns with SDS sample buffer and subjected to SDS-PAGE. ${ }^{32} \mathrm{P}$-incorporation was analyzed by autoradiography and quantitated with an LKB laser densitometer.

\section{Results \\ Colocalization of neuron-induced AChR clusters with phosphotyrosine}

To study the role of muscle innervation on tyrosine phosphorylation of the acetylcholine receptor, ciliary ganglion neurons from embryonic day 8 or day 9 chicks were added to chick hindlimb myotube cultures and allowed to form synapses. These neurons have previously been demonstrated to form functional synaptic connections with myotubes in vitro and to induce the $\mathrm{AChR}$ to cluster beneath the nerve terminal (Cohen and Fischbach, 1977; Role et al., 1985, 1987). In Figure 1A, a nerveinduced AChR cluster is shown at the site of a nerve-muscle contact. Double labeling these nerve-induced AChR clusters with rhodamine-conjugated $\alpha$-bungarotoxin and anti-phosphotyrosine antibodies demonstrates that the AChR clusters (Fig. $1 B$ ) colocalize with a high level of phosphotyrosine staining (Fig. 1C). Similar results were seen in Xenopus nerve-muscle cel cocultures (data not shown). This experiment shows that nerveinduced AChR clusters in cell culture stain with anti-phosphotyrosine antibodies in a manner similar to that seen in innervated skeletal muscle in vivo (Qu et al., 1990) and with agrin-induced AChR clusters in vitro (Wallace et al., 1991).

\section{Nerve-induced tyrosine phosphorylation of the AChR}

To compare nerve- and agrin-induced tyrosine phosphorylation of the $\mathrm{AChR}$, we partially purified $\mathrm{AChR}$ subunits from chick myotube cultures using acetylcholine affinity chromatography 


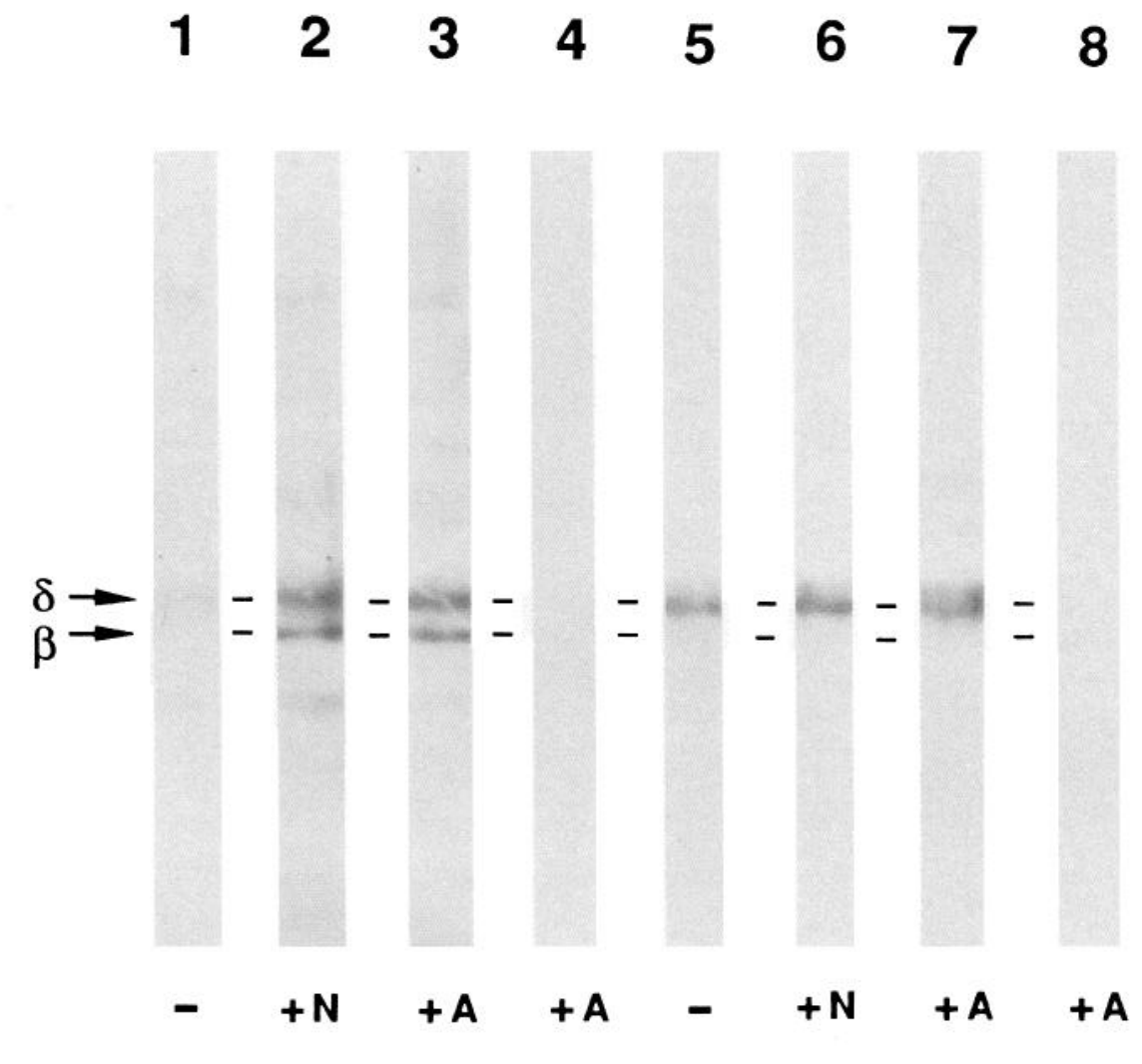

Figure 3. Immunoblot of the AChR isolated from innervated and agrintreated myotubes with anti-phosphotyrosine antibodies. Partially purified preparations of the AChR from myotubes cultured (lane 1,5), chick neuron-muscle cell cocultures (lanes 2 and 6) and agrin-treated myotube cultures (lanes 3, 4, 7, and 8 ) were isolated by acetylcholine affinity chromatography. Lanes $1-4$ were analyzed by immunoblot techniques using affinity-purified anti-phosphotyrosine antibodies and lane 5-8 were analyzed by immunoblotting with a monoclonal antibody $88 \mathrm{~b}$ against the AChR $\delta$ subunit. Controls were purified from chick myotubes in the presence of carbamylcholine to specifically block absorption of the AChR to the affinity column (lanes 4 and 8 ). and analyzed the tyrosine phosphorylation of these subunits. The subunits of the purified AChR were identified based on their cross-reactivity with monoclonal antibodies, their apparent molecular masses, and changes in migration in SDS polyacrylamide gels after boiling the sample (Fig. 2). The $\alpha, \beta$, and $\delta$ subunits were identified as $40 \mathrm{kDa}, 52 \mathrm{kDa}$, and $56 \mathrm{kDa}$ proteins, respectively (Fig. 2) (Wallace et al., 1991). We have not been able to detect the $\gamma$ subunit using monoclonal antibodies, most likely due to the known sensitivity of the $\gamma$ subunit to proteolysis or due to a lack of cross-reactivity of the antibodies tested (Huganir and Racker, 1980; Merlie and Sebbane, 1981). As we have previously described (Wallace et al., 1991), when the isolated AChR was boiled prior to SDS-PAGE, the $\delta$ subunit changed its apparent molecular mass to a protein of $48 \mathrm{kDa}$ (data not shown). This change in apparent molecular mass is likely due to proteolysis (Huganir and Racker, 1980; Merilie and Sebbane, 1981). Control preparations of the chick AChR purified on the affinity column in the presence of $50 \mathrm{~mm}$ carbamylcholine to prevent adsorption of the AChR did not show any labeling with AChR subunit antibodies (data not shown).

The tyrosine phosphorylation of the AChR purified from innervated and agrin-treated chick myotube cultures was analyzed using immunoblot techniques with anti-phosphotyrosine antibodies (Fig. 3, lanes 1-4). Both innervation and agrin treatment of myotubes increased the tyrosine phosphorylation of the AChR $\beta$ and $\delta$ subunits. The stimulation of tyrosine phosphorylation of the $\beta$ subunit by both neurons and agrin was variable and ranged from two- to eightfold depending on the experiment. This variability in the fold stimulation of tyrosine phosphorylation by neurons and agrin appeared to be inversely related to the basal tyrosine phosphorylation of the receptor subunits. In previous experiments (Wallace et al., 1992) we had not seen any tyrosine phosphorylation of the $\delta$ subunit due to the fact that we boiled the SDS sample buffer prior to SDS-PAGE. This appears to result in the proteolytic nicking of the $\delta$ subunit and the loss of the tyrosine phosphorylation site. Immunobloting with monoclonal antibody $88 \mathrm{~b}$ against the $\mathrm{AChR} \delta$ subunit (Fig. 3 , lanes 5-8) confirmed that each lane was loaded with the same amount of AChR. Control preparations of chick AChR purified on the affinity column in the presence of $50 \mathrm{~mm}$ carbamylcholine to prevent adsorption of AChR showed no labeling with either the anti-phosphotyrosine antibodies (Fig. 3, lane 4) or with the monoclonal antibody against the AChR $\delta$ subunit (Fig. 3, lane $8)$. These results demonstrate that the acetylcholine affinity column is specific for acetylcholine receptor and that the phosphotyrosine containing proteins are the $\beta$ and $\delta$ subunits. Immunoblot of total membrane proteins with anti-phosphotyrosine antibody showed no detectable increase in tyrosine phosphorylation of any other protein after innervation or agrin treatment of myotubes (data not shown). Thus, the increase of tyrosine phosphorylation of the AChR induced by innervation and agrin treatment appeared to be relatively specific and not part of a widespread increase in tyrosine phosphorylation of myotube proteins.

To investigate further the effect of innervation and agrin treatment on AChR phosphorylation, myotubes were cocultured with neurons or treated with agrin and then labeled with ${ }^{32} \mathrm{P}$-orthophosphate. Acetylcholine receptors were purified using acetylcholine affinity chromatography followed by immunoprecipitation with a subunit specific monoclonal antibody (mAb $88 \mathrm{~b}$ ). Figure 4 shows that the AChR is basally phosphorylated on the $\beta$ and $\delta$ subunits and that the phosphorylation on these subunits was increased after the myotubes had been innervated (Fig. 4, lane 2 ; 1.61 -fold $\pm 0.42, n=6$ ) or treated with agrin (Fig. 4 , 


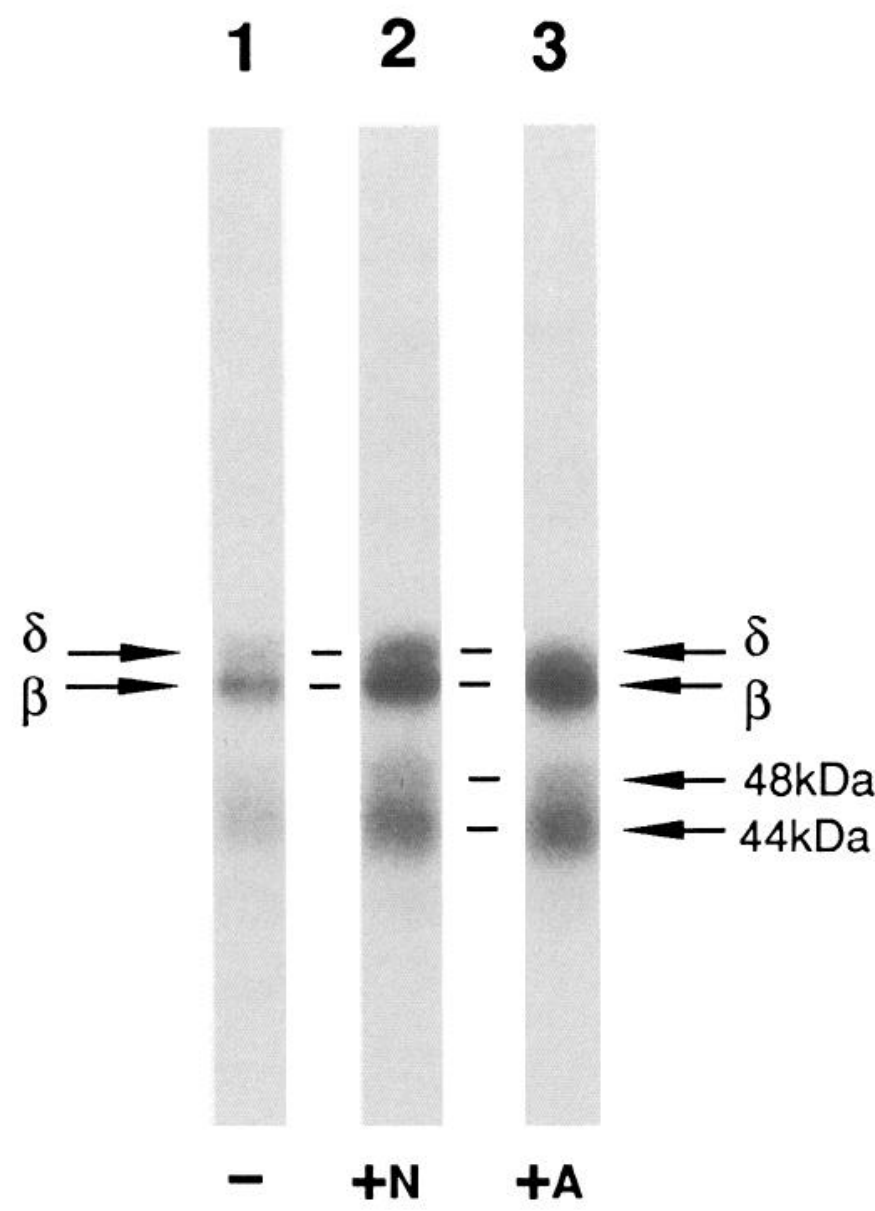

Figure 4. The AChR isolated from innervated and agrin-treated myotubes prelabeled with ${ }^{32} \mathrm{P}$ - orthophosphate. ${ }^{32} \mathrm{P}$-orthophosphate was added to cultured chick myotubes (lane 1), cocultured chick neurons and myotubes (lane 2), and cultured chick myotubes treated with agrin (lane 3 ) in phosphate-free medium overnight. Agrin and neurons were added 12 and $48 \mathrm{hr}$, respectively, prior to harvesting the myotubes. The AChR was purified by acetylcholine affinity chromatography and was immunoprecipitated with the $\delta$ subunit-specific monoclonal antibody $88 \mathrm{~b},{ }^{32} \mathrm{P}$-labeling on the AChR $\beta$ and $\delta$ subunits increases after the myotubes were innervated or treated with agrin. The agrin-induced increase in phosphorylation is similar to the innervation-induced increase in phosphorylation.

lane $3 ; 1.7$-fold $\pm 0.24, n=6$ ). In addition, small increases in ${ }^{32} \mathrm{P}$-labeling of two polypeptides with apparent molecular masses of $44 \mathrm{kDa}$ and $48 \mathrm{kDa}$ were also observed. The identity of these two proteins are not clear, although they may be the $\gamma$ subunit or breakdown products of the $\beta, \gamma$, or $\delta$ subunits. As with the neuron- and agrin-induced tyrosine phosphorylation of the $\beta$ and $\delta$ subunits, the nerve- and agrin-stimulated phosphorylation of the $\beta$ and especially the $\delta$ subunit was somewhat variable. No phosphoproteins were detected in control preparations of AChR purified on acetylcholine affinity chromatography in the presence of $50 \mathrm{~mm}$ carbamylcholine to prevent adsorption of the AChR. In addition, no phosphoproteins were observed when the AChR was isolated on an immunoaffinity column in the presence of excess purified Torpedo AChR to prevent absorption of the AChR to the column (data not shown).

To compare the sites phosphorylated on the $\beta$ and $\delta$ subunits in response to innervation or agrin, the ${ }^{32} \mathrm{P}$-labeled subunits isolated from cultured chick myotubes were excised from the
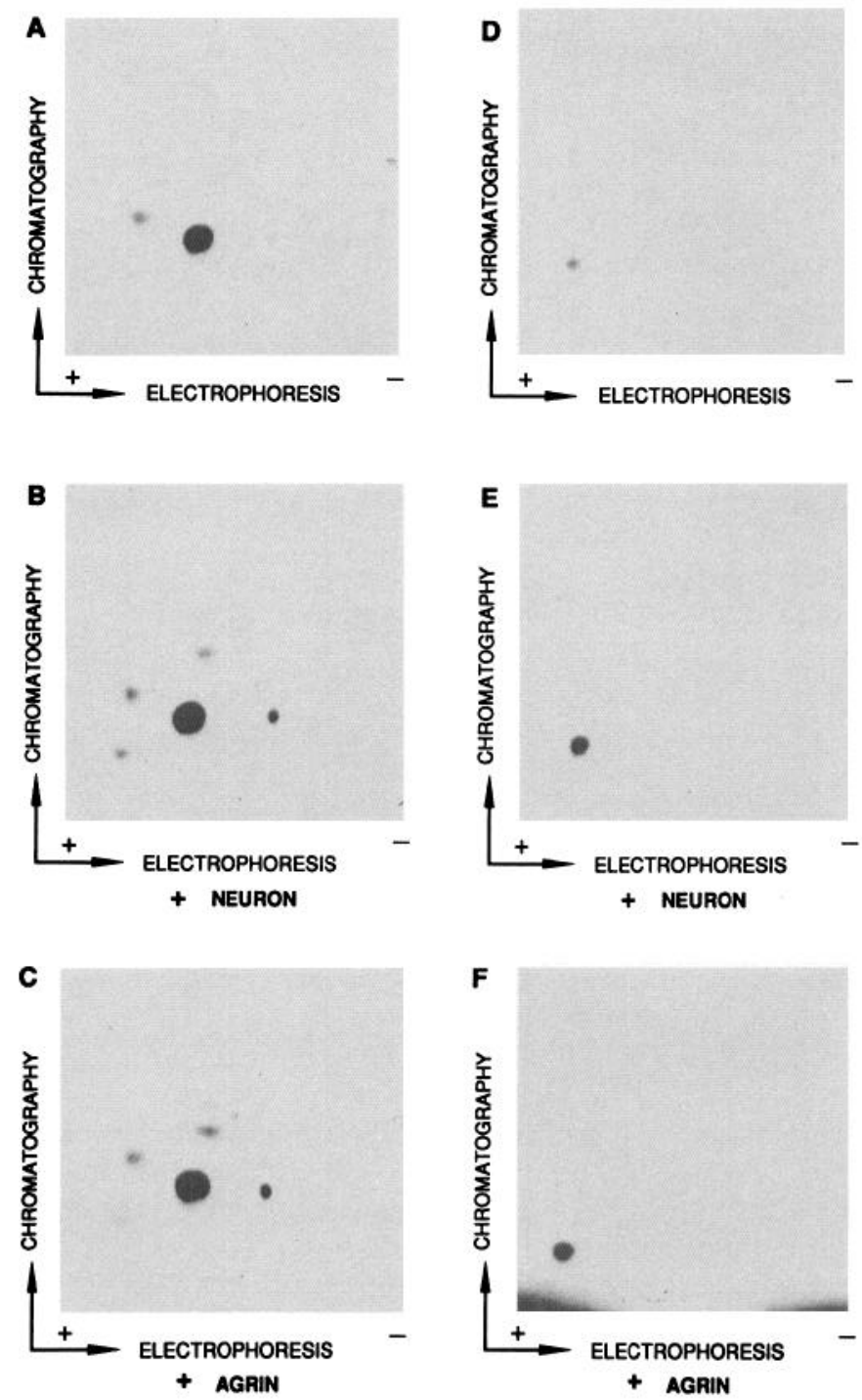

Figure 5. Two-dimensional thermolytic phosphopeptide maps of the AChR $\beta$ and $\delta$ subunits isolated from innervated and agrin-treated myotubes. Myotube cultures were incubated with $5 \mathrm{mCi} / \mathrm{ml}{ }^{32} \mathrm{P}$-orthophosphate for $12 \mathrm{hr}$ in the presence or absence of neurons or agrin. The AChR was isolated by affinity chromatography and immunoprecipitation, and then the subunits were separated by SDS-PAGE and localized by autoradiography. Because the $\beta$ and $\delta$ subunits were hard to resolve, the two subunits were combined for phosphopeptide map analysis. Excised gel pieces were subjected to thermolytic phosphopeptide mapping. The phosphopeptide maps of the AChR $\beta$ and $\delta$ subunits from chick myotubes with innervation $(B)$ and agrin treatment $(C)$ were very similar and showed increased phosphorylation of several major phosphopeptides compared to the control $(A) . D-F$, Phosphopeptide maps of the $44 \mathrm{kDa}$ proteins in Figure 4 from control, innervated, and agrintreated myotube cultures.

polyacrylamide gel and subjected to a limit digestion with thermolysin, and the resultant phosphopeptides were analyzed by two-dimensional thin-layer chromatography. Due to the difficulty in resolving the $\beta$ and $\delta$ subunits and the limited amounts of ${ }^{32} \mathrm{P}$ incorporated into these subunits, the $\beta$ and $\delta$ subunits were combined for phosphopeptide map and phosphoamino acid analysis. The phosphopeptide maps of AChR $\beta$ and $\delta$ subunits from innervated (Fig. $5 B$ ) and agrin-treated cells (Fig. $5 C$ ) showed a similar pattern, with significant increases in the phosphorylation of several phosphopeptides compared to the control 
phosphopeptide map (Fig. 5A). The peptide maps shown in Figure $5 A-C$ were overexposed to emphasize the similar phosphopeptide map pattern of innervated and agrin-induced phosphorylation of the $\beta$ and $\delta$ subunits. On shorter exposures, the major basal phosphorylation site seen in the control sample is also increased after innervation or agrin treatment. The phosphopeptide maps of the $44 \mathrm{kDa}$ protein in Figure 4 are shown in Figure $5 D-F$. This protein had one major phosphopeptide, which increased in ${ }^{32} \mathrm{P}$-labeling after innervation (Fig. $5 E$ ) and agrin treatment (Fig. $5 F$ ). The $48 \mathrm{kDa}$ protein had a similar phosphopeptide map to the $44 \mathrm{kDa}$ protein, suggesting that these two proteins are related to each other (data not shown). This phosphopeptide map analysis was repeated twice with similar results. These results demonstrate that nerve and agrin increased the phosphorylation of the AChR on similar phosphopeptides, suggesting that nerve- and agrin-induced phosphorylation of the AChR may utilize similar mechanisms.

Phosphoamino acid analysis of the combined ${ }^{32} \mathrm{P}$-labeled AChR $\beta$ and $\delta$ subunits isolated from innervated and agrintreated myotubes showed increases in phosphorylation on serine and tyrosine residues (Fig. 6). Quantitation with a PhosphoImager 4000E system (Molecular Dynamics) and IMAGEQUANT software showed that agrin-induced phosphorylation of the AChR increased serine phosphorylation by $190 \%$ and tyrosine phosphorylation by $330 \%$. Nerve-induced phosphorylation of the AChR increased serine phosphorylation by $199 \%$ and tyrosine phosphorylation by $270 \%$. Phosphoamino acid analyses were repeated three times with similar results.

\section{Developmental regulation of tyrosine phosphorylation at chick neuromuscular junction}

To study the regulation of tyrosine phosphorylation during innervation of chick muscle in vivo, we examined immunofluorescent staining of muscle frozen sections from chicks at embryonic days $4,5,6,7,9,14,16,18$, postnatal day 1 , and in the adult using monoclonal anti-phosphotyrosine antibodies and rhodamine-conjugated $\alpha$-bungarotoxin. Phosphotyrosine staining directly colocalized with the AChR staining of chick hindlimb muscle and appeared during embryogenesis as soon as AChR clusters were observed. AChR clusters are first observed on embryonic day 5 (Fig. $7 A$ ) and colocalize with phosphotyrosine staining (Fig. $7 B$ ). By embryonic day 7 (Fig. $7 C$ ), the phosphotyrosine level was close to that of adult chick (Fig. $7 D$ ). In Figure 7, $C$ and $D$ are double and triple exposures, respectively, in which the rhodamine and fluorescein staining of the muscle has been artificially separated to show the AChR and phosphotyrosine staining side by side for comparison.

\section{Discussion}

Neuromuscular junction differentiation is a result of inductive interactions between motor neurons and muscle fibers (Dennis, 1981). Prior to innervation, AChRs and other synaptic proteins are diffusely located on the surface of the muscle cell membrane (Schuetze and Role, 1987). Upon innervation, the AChR as well as other synaptic proteins begin to aggregate beneath the nerve terminal (Anderson et al., 1977; Frank and Fischbach, 1979; Froehner et al., 1981; Bloch and Hall, 1983). A variety of experiments have suggested that a synaptic extracellular matrix protein induces $\mathrm{AChR}$ clustering at the synapse, and recent studies have provided evidence that this nerve-induced aggregation is mediated by the neuronal extracellular matrix protein agrin (McMahon, 1990). Agrin is transported along motor neu-

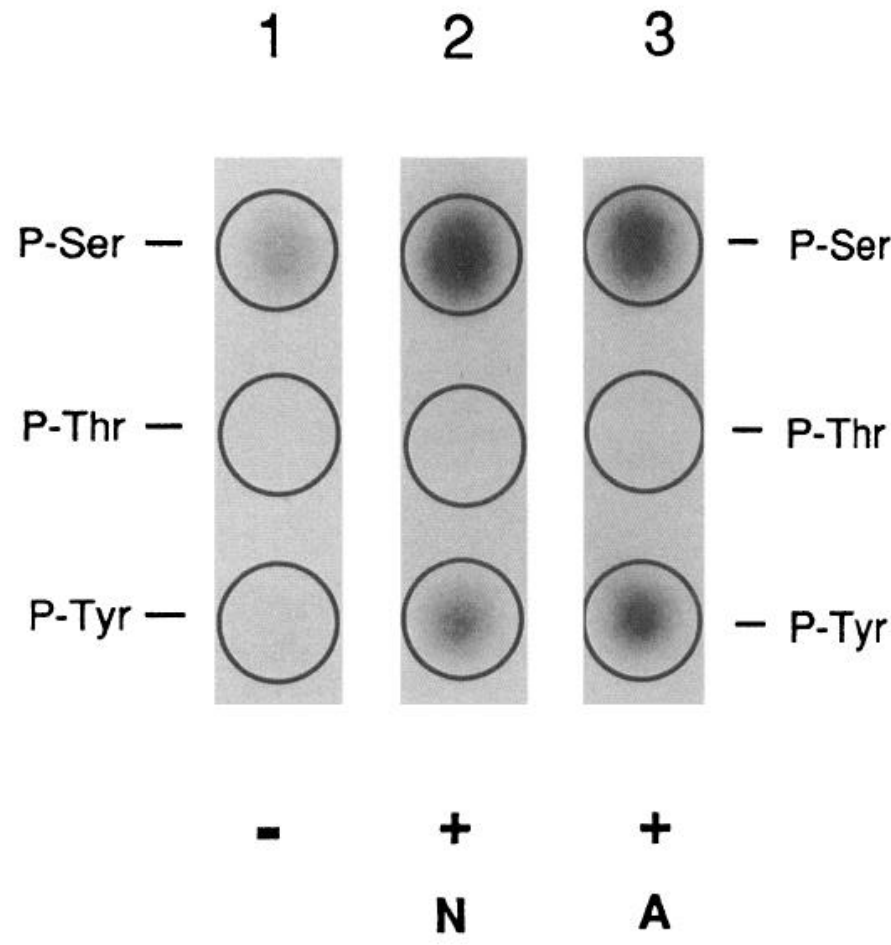

Figure 6. Phosphoamino acid analysis of the AChR $\beta$ and $\delta$ subunits isolated from innervated and agrin-treated cultured chick myotubes. The ${ }^{32} \mathrm{P}$-labeled AChR $\beta$ and $\delta$ subunits in Figure 4 from control, innervated, and agrin-treated cultured myotubes were excised and incubated with thermolysin. Because the $\beta$ and $\delta$ subunits were hard to resolve, the two subunits were combined for phosphoamino acid analysis. The digests were then subjected to phosphoamino acid analysis (circles indicate the positions of the nonradioactive phosphoamino acid). The phosphoamino acid analysis shows that both innervation and agrininduced phosphorylation increases of the $\mathrm{AChR} \beta$ and $\delta$ subunits are on serine and tyrosine residues.

rons and deposited at the synaptic basal lamina (Magill-Solc and McMahan, 1990; Cohen and Godfrey, 1992; Reist et al., 1992; Hoch et al., 1993). Purified or recombinant agrin induces AChR aggregation on myotubes in culture (Wallace, 1986, 1989; Nitkin et al., 1987; Campanelli et al., 1991; Tsim et al., 1992). Moreover, nerve-induced aggregation is inhibited by antibodies to agrin (Reist et al., 1992). The mechanism of agrin-induced clustering of synaptic proteins, however, is unclear. Recent studies have demonstrated that agrin regulates tyrosine phosphorylation of the AChR and have suggested that tyrosine phosphorylation may play a role in agrin-induced receptor clustering (Wallace et al., 1991). In addition, this idea is consistent with experiments that have examined latex bead- and electric fieldinduced AChR clustering in muscle cells in culture (Baker et al., 1992; Baker and Peng, 1993; Peng et al., 1993). These studies show that high levels of phosphotyrosine are colocalized at the site of AChR clusters. Moreover, tyrosine kinase inhibitors block the latex bead- and electric field-induced AChR clustering (Peng et al., 1993). These results support the idea that tyrosine phosphorylation may play a role in agrin- and nerve-induced aggregation of the AChR in muscle.

In this study we examined the regulation of phosphorylation of the AChR by innervation of myotubes in culture and compared it with agrin-induced phosphorylation. By immunofluorescent double labeling, we found phosphotyrosine staining occurred at nerve-induced $\mathrm{AChR}$ clusters as we had previously 

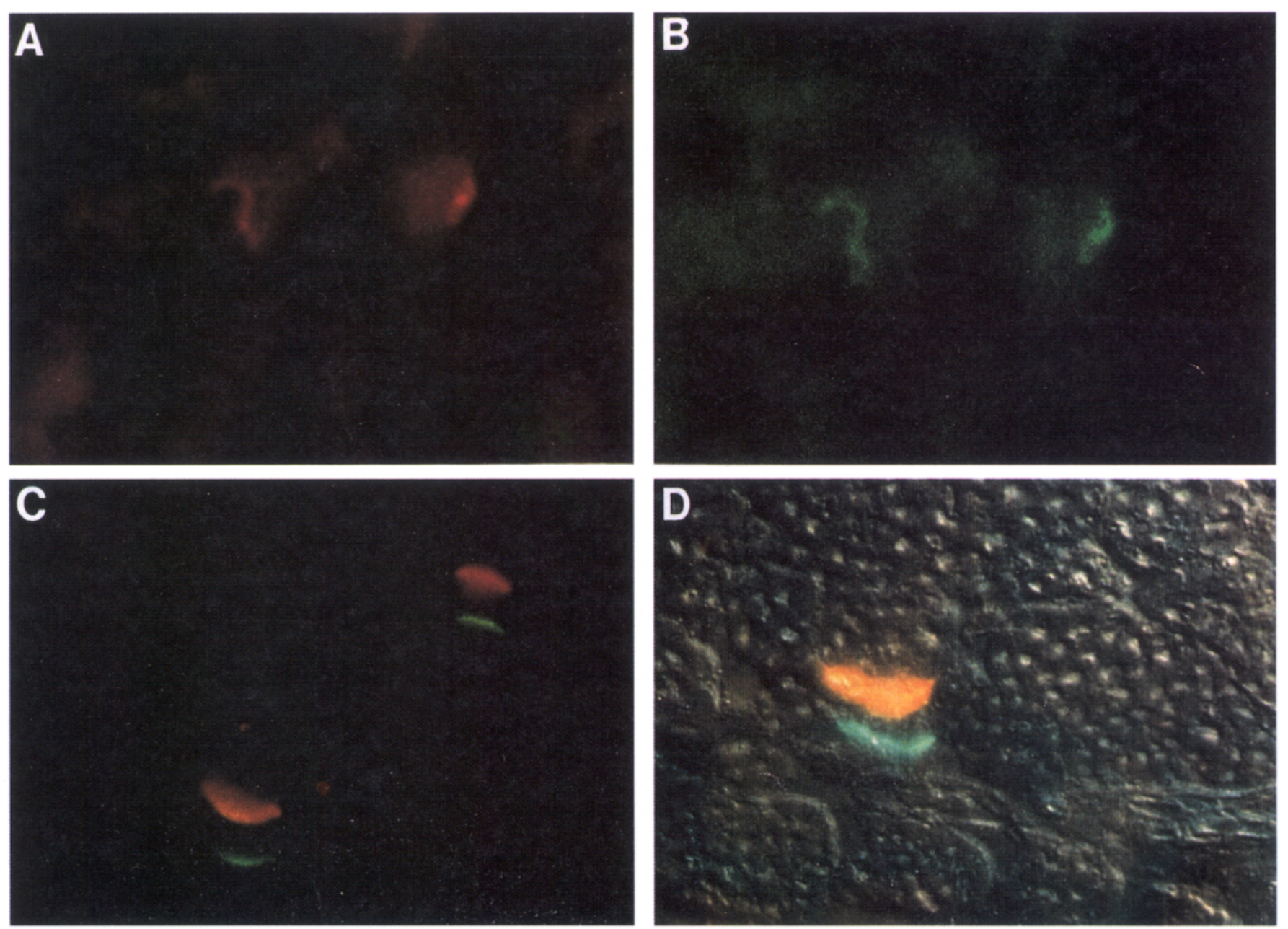

Figure 7. Developmental regulation of tyrosine phosphorylation of the AChR at the chick neuromuscular junction. Cryostat sections from prenatal and postnatal chick leg muscle were fixed and double labeled with rhodamine-conjugated $\alpha$-bungarotoxin and with a monoclonal antibody against phosphotyrosine (PY20) and fluorescein-conjugated secondary antibody. Day 5 chick embryo leg muscle stained with rhodamine-conjugated $\alpha$-bungarotoxin $(A)$, and with anti-phosphotyrosine antibodies $(B)$. The rhodamine and fluorescein labeling were artificially separated to allow sideby-side comparison of the staining pattern in day 7 chick embryo $(C)$ and adult chick $(D)$. Tyrosine phosphorylation of the AChR of chick hindlimb muscle appeared during embryogenesis as soon as the AChR clusters were observed.

found with agrin-induced AChR clusters (Wallace et al., 1991). Both innervation and agrin treatment of myotubes increased phosphorylation of the $\beta$ and $\delta$ subunits of the AChR on both tyrosine and serine residues. In our previous experiments it was found that agrin-induced tyrosine phosphorylation of the AChR occurred only on the $\beta$ subunit (Wallace et al., 1991). This discrepancy resulted from the apparent proteolytic nicking of the $\delta$ subunit and loss of the tyrosine phosphorylation site due to our previous protocol, which involved boiling the samples prior to SDS-PAGE. In addition, innervation and agrin treatment increased phosphorylation of the $\mathrm{AChR} \beta$ and $\delta$ subunits on similar phosphopeptides. These results suggest that agrin may mediate the nerve-induced tyrosine phosphorylation of the $\mathrm{AChR}$ seen in vitro and that agrin may be involved in developmental regulation of tyrosine phosphorylation at the neuromuscular junction. These results are consistent with the developmental time course of tyrosine phosphorylation at the chick neuromuscular junction where tyrosine phosphorylation colocalizes with AChR clusters as soon as they are detected.

These developmental studies in chick contrasts with our previous data in rat, where tyrosine phosphorylation at the neuromuscular junction appears late in development, at postnatal day 4, 10 d after nerve-induced clustering of the AChR (Qu et al., 1990). Recent developmental studies of the expression of agrin have shown that the mRNA levels of active forms of agrin are relatively high in the spinal cord of embryonic rats and that agrin protein has been detected in muscle as soon as receptor clusters occur at prenatal day 16 (Hoch et al., 1993). Therefore, other factors may be involved in the regulation of tyrosine phosphorylation at the neuromuscular junction in rats. It is interesting to note, however, that expression of the form of agrin (z8 ) that is most active in clustering of the $A C h R$ in vitro increases in parallel with the appearance of tyrosine phosphorylation at the rat neuromuscular junction (Hoch et al., 1993).

\section{References}

Anderson MJ, Cohen MW, Zorychta E (1977) Effects of innervation on the distribution of acetylcholine receptors on cultured muscle cells. J Physiol (Lond) 268:731-756.

Baker LP, Peng HB (1993) Tyrosine phosphorylation and acetylcholine receptor cluster formation in cultured Xenopus muscle cells. J Cell Biol 120:185-195.

Baker LP, Chen Q, Peng HB (1992) Induction of acetylcholine receptor clustering by native polystyrene beads. Implication of an endogenous muscle-derived signalling system. J Cell Sci 102:543-555. 
Bloch RJ, Hall ZW (1983) Cytoskeletal components of the vertebrate neuromuscular junction: vinculin, $\alpha$-actinin, and filamin. J Cell Biol 97:217-223.

Campanelli JT, Hoch W, Rupp F, Kreiner T, Scheller RH (1991) Agrin mediates cell contact-induced acetylcholine receptor clustering. Cell 67:909-916.

Cohen MW, Godfrey EW (1992) Early appearance of and neuronal contribution to agrin-like molecules at embryonic frog nerve-muscle synapses formed in culture. J Neurosci 12:2982-2992.

Cohen SA, Fischbach GD (1977) Cluster of acetylcholine receptors located at identified nerve-muscle synapses in vitro. Dev Biol 59:2438.

Dennis MJ (1981) Development of the ncuromuscular junction: inductive interactions between cells. Annu Rev Neurosci 4:43-68.

Edelman AM, Blumenthal PK, Krebs EG (1987) Protein serine/threonine kinases. Annu Rev Biochem 56:567-613.

Ferns M, Hoch W, Campanelli JT, Rupp F, Hall ZW, Scheller RH (1992) RNA splicing regulates agrin-mediated acetylcholine receptor clustering activity on cultured myotubes. Neuron 8:1079-1086.

Ferns MJ, Campanelli JT, Hoch W, Scheller RH, Hall ZW (1993) The ability of agrin to cluster AChRs depends on alternative splicing and on cell surface proteoglycans. Neuron 11:491-502.

Fischbach GD (1972) Synapse formation between dissociated nerve and muscle cells in low density cell cultures. Dev Biol 28:407-429.

Frank E, Fischbach GD (1979) Early events in neuromuscular junction formation in vitro. Induction of acetylcholine receptor clusters in the postsynaptic membrane and morphology of newly formed nervemuscle synapses. J Cell Biol 83:143-158.

Froehner SC, Coulbrandsen V, Hyman C, Jeng AY, Neubig RR, Cohen JB (1981) Immunofluorescence localization at the mammalian neuromuscular junction of the $M_{r} 43,000$ protein of Torpedo postsynaptic membrane. Proc Natl Acad Sci USA 78:5230-5234.

Galzi JL, Revah F, Bessis A, Changeux JP (1991) Functional architecture of the nicotinic acetylcholine receptor: from electric organ to brain. Annu Rev Pharmacol 31:37-72.

Godfrey EW, Nitkin RM, Wallace BG, Rubin LL, McMahan UJ (1984) Components of Torpedo electric organ and muscle that cause aggregation of acetylcholine receptors on cultured muscle cells. J Cell Biol 99:615-627.

Hirano AA, Greengard P, Huganir RL (1988) Protein tyrosine kinase activity and its endogenous substrates in rat brain: a subcellular and regional survey. J Neurochem 50:1147-1155.

Hoch W, Ferns M, Campanelli JT, Hall ZW, Scheller RW (1993) Developmental regulation of highly active alternatively spliced forms of agrin. Neuron 11:479-490.

Hopfield JF, Tank DW, Greengard P, Huganir RL (1988) Functional modulation of the nicotinic acetylcholine receptor by tyrosine phosphorylation. Nature 336:677-680.

Huganir RL (1987) Phosphorylation of purified ion channel protein. In: Neuromodulation (Kaczmarek L, Levitan I, eds), pp 86-99. New York: Raven.

Huganir RL, Greengard P (1983) cAMP-dependent protein kinase phosphorylates the nicotinic acetylcholine receptor. Proc Natl Acad Sci USA 80:1130-1134.

Huganir RL, Racker E (1980) Endogenous and exogenous proteolysis of the acetylcholine receptor from Torpedo californica. J Supramol Struct 14:13-19.

Huganir RL, Miles K, Greengard P (1984) Phosphorylation of the nicotinic acetylcholine receptor by an endogenous tyrosine-specific protein kinase. Proc Natl Acad Sci USA 81:6963-6972.

Laemmli UK (1970) Cleavage of structural proteins during the assembly of the head of bacteriophage T4. Nature 227:680-685.

Magill-Solc C, McMahan UJ (1990) Synthesis and transport of agrinlike molecules in motor neurons. J Exp Biol 153:1-10.

McMahan UJ (1990) The agrin hypothesis. Cold Spring Harb Symp Quant Biol 55:407-418
Merlie JP, Sebbane R (1981) Acetylcholine receptor subunits transit a precursor pool before acquiring $\alpha$-bungarotoxin binding activity. $\mathrm{J}$ Biol Chem 256:3605-3608.

Miles K, Greengard P, Huganir RL (1989) Calcitonin gene-related peptide regulates phosphorylation of the nicotinic acetylcholine receptor in rat myotubes. Neuron 2:1517-1524.

Miles K, Audigier SSM, Greengard P, Huganir RL (1993) Autoregulation of phosphorylation of the nicotinic acetylcholine receptor. $\mathrm{J}$ Neurosci 14:3271-3279.

Nitkin RM, Smith MA, Magill C, Fallon JR, Yao Y-MM, Wallace BG, McMahan UJ (1987) Identification of agrin, a synaptic organizing protein from Torpedo electric organ. J Cell Biol 105:2471-2478.

Peng HB, Baker LP, Dai Z (1993) A role of tyrosine phosphorylation in the formation of acetylcholine receptor clusters induced by electric fields in cultured Xenopus muscle cells. J Cell Biol 120:197-204.

Qu Z, Moritz E, Huganir RL (1990) Regulation of tyrosine phosphorylation of the nicotinic acetylcholine receptor at the rat neuromuscular junction. Neuron 2:367-378.

Raymond LA, Blackstone CD, Huganir RL (1993) Phosphorylation of amino acid neurotransmitter receptors in synaptic plasticity. Trends Neurosci 16:147-153.

Reist NE, Werle MJ, McMahan UJ (1992) Agrin released by motor neurons induces the aggregation of acetylcholine receptors at neuromuscular junctions. Neuron $8: 865-868$

Role LW, Matossian VR, O'Brien R, Fischbach GD (1985) On the mechanism of acetylcholine receptor accumulation at newly formed synapses on chick myotubes. J Neurosci 5:2197-2204.

Role LW, Roufa DG, Fischbach GD (1987) The distribution of acetylcholine receptor clusters and sites of transmitter release along chick ciliary ganglion neurite-myotube contacts in culture. J Cell Biol 104: 371-379.

Ross A, Rapuano M, Prives J (1988) Induction of phosphorylation and cell surface redistribution of acetylcholine receptors by phorbol ester and carbamylcholine in cultured chick muscle cells. J Cell Biol 107:1139-1145.

Rupp F, Payan DG, Magill-Solc C, Cowan DM, Scheller RH (1991) Structure and expression of a rat agrin. Neuron 6:811-823.

Safran A, Eisenherg RS, Neumann D, Fuchs S (1987) Phosphorylation of the acetylcholine receptor by protein kinase $\mathrm{C}$ and identification of the phosphorylation site within the receptor d subunit. J Biol Chem 262:10506-10510.

Schuetze SM, Role LW (1987) Developmental regulation of nicotinic acetylcholine receptors. Annu Rev Neurosci 10:403-457.

Swope SL, Moss SJ, Blackstone CD, Huganir RL (1992) Phosphorylation of ligand-gated ion channels: a possible mode of synaptic plasticity. FASEB J 6:2514-2523.

lowbin H, Staehelin I, Gordon J (1979) Electrophoretic transfer of proteins from polyacrylamide gels to nitrocellulose sheets: procedure and some applications. Proc Natl Acad Sci USA 76:4350-4354.

Tsim KW, Ruegg MA, Escher G, Kröger S, McMahan UJ (1992) cDNA that encodes active agrin. Neuron 8:677-689.

Wallace BG (1986) Aggregating factor from Torpedo electric organ induces patches containing acetylcholine receptors, acetylcholinesterase, and butyrylcholinesterase on cultured myotubes. J Cell Biol 102:783-794.

Wallace BG (1989) Agrin-induced specializations contain cytoplasmic, membrane, and extracellular matrix-associated components of the postsynaptic apparatus. J Neurosci 9:1294-1302.

Wallace BG, Qu Z, Huganir RL (1991) Agrin induces phosphorylation of the nicotinic acetylcholine receptor. Neuron 6:869-878.

Zavoico GB, Comerci C, Subers E, Egon JJ, Huang CK, Feinstein MB Smilowitz H (1984) cAMP, not $\mathrm{Ca}^{2+} /$ calmodulin, regulates the phosphorylation of acetylcholine receptor in Torpedo californica electroplax. Biochim Biophys Acta 770:225-229. 